\title{
Anomalous Origin of the Right Coronary Artery from the Left Sinus Valsalva with Coronary Ectasia
}

\author{
Nihat Söylemez ${ }^{1}$, Recep Demirbağ ${ }^{1}$, Tuncay Hazırolan², Onur Akpınar ${ }^{3 *}$ \\ ${ }^{1}$ Department of Cardiology, Harran University, Şanlıurfa, Turkey; ${ }^{2}$ Department of Radiology, Hacettepe University, Ankara, Turkey; \\ ${ }^{3}$ Department of Cardiogy, Gaziantep Medical Park Hospital, Gaziantep, Turkey. \\ Email: *onur_akpinar@yahoo.com
}

Received January $26^{\text {th }}, 2011$; revised April $6^{\text {th }}, 2011$; accepted June $27^{\text {th }}, 2011$.

\begin{abstract}
The abnormal origin of the right coronary artery from the left aortic sinus coursing between the aorta and the pulmonary trunk is a rare congenital anomaly. It may remain asymptomatic or may result in cardiac morbidity or mortality. In the past, an anomalous origin of the right coronary artery from the left sinus of Valsalva was considered a benign finding; it is now evident that this anomaly can be associated with atypical chest pain, myocardial ischemia, and sudden death. We thought that; the diagnosis of left sinus Valsalva aneurysm, described by transtorasic echocardiography and transeusophageal echocardiography, might need demonstrated advanced scanning techniques.
\end{abstract}

Keywords: Congenital Anomaly, Coronary Ectasia, Echocardiography, Multi Detector Computerize Tomography

\section{Introduction}

Coronary artery anomalies are a relatively rare condition. The clinical presentation of coronary artery anomalous is variable, ranging from being asymptomatic to symptoms of syncope, unstable angina, myocardial ischemia and sudden death. The incidence of anomalous coronary arteries has been reported to be approximately $1 \%$ to $2 \%$ [1]. Variations in the origin and/or course of anomalous coronary arteries are well documented in the literature but in this case, "interestingly" there was an anomalous right coronary artery arising from the left coronary sinus with proximal ectasia.

\section{Case Presentation}

A 56-year-old woman with a history of typical angina on effort and without history of smoking, hypertension and diabetes mellitus was admitted to our hospital. The presenting symptoms had begun approximately since one year however chest pain became more intensive dated from last one week. On admission, her heart rate were 68 beat/min, her blood pressure were $110 / 72 \mathrm{mmHg}$ and her respiratory rate were $22 \mathrm{breath} / \mathrm{min}$. Physical examination was normal. Electrocardiography showed minimal ST depression and T wave inversion in DII-DIII and AVF leads. The results of the laboratory revealed crea- tine phosphokinase isoenzyme of $117 \mathrm{ng} / \mathrm{mlt}$, troponin I of $0.02 \mathrm{ng} / \mathrm{mlt}$, total cholesterol of $224 \mathrm{mg} / \mathrm{dL}$, high density lipoprotein cholesterol of $53 \mathrm{mg} / \mathrm{dL}$, low density lipoprotein-cholesterol of $162 \mathrm{mg} / \mathrm{dL}$, and triglycerides of $45 \mathrm{mg} / \mathrm{d}$. Other biochemistry and blood test values were within normal limits. Exercise treadmill testing was positive. Coronary angiography was recommended but the patient didn't accept it.

Normal systolic (Ejection fractions: 58\% with Simpson's) and diastolic (E/A > 1) function, normal wall motion and suspicious images for aneurysm of left sinus valsalva in transtorasic echocardiography (TTE). Transeusophageal echocardiography (TEE) findings were similar to TTE for the aneurysm of left sinus valsalva (Figure 1).

Then the right coronary artery which arise from the left sinus valsalva and courses between the ascending aorta and pulmonary artery with proximal ectasia demonstrated by multi detector computerize tomography (MDCT) heart angiography (Figure 2 (a) and (b)).

\section{Discussion}

In $0.03 \%-0.17 \%$ of patients undergoing angiography, the right coronary arises from the left sinus of valsalva as a separate vessel or as a branch of a single coronary 


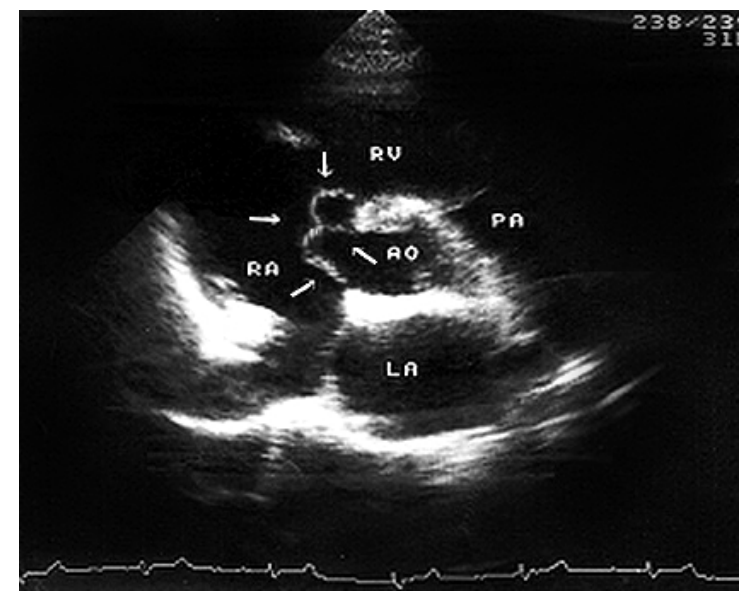

Figure 1. Transeusophageal echocardiography showed the aneurysm of left sinus valsalva.

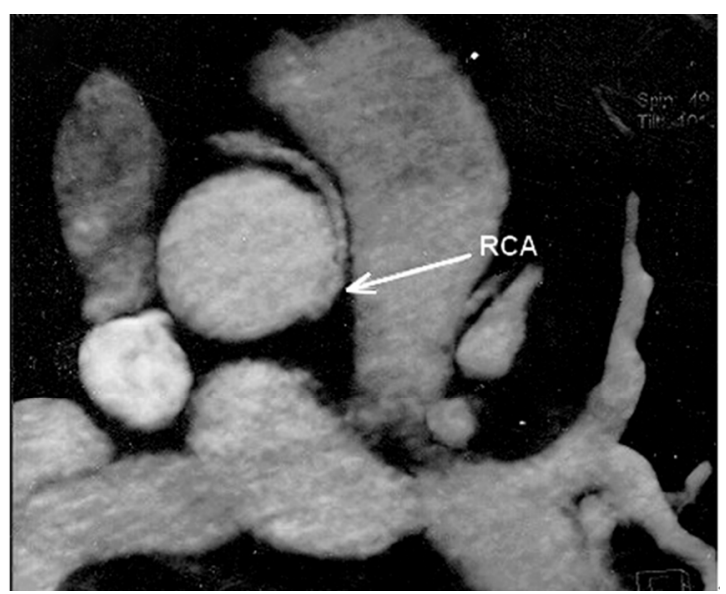

(a)

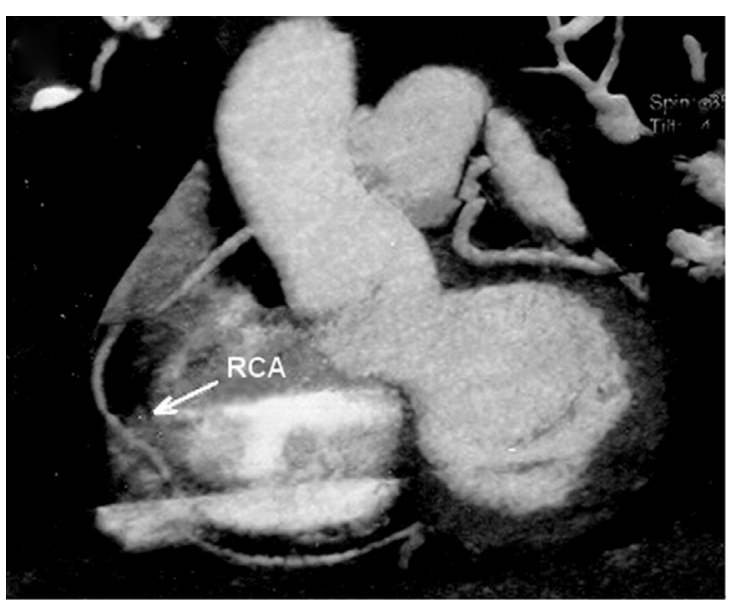

(b)

Figure 2(a) and (b). The right coronary artery which arises from the left sinus valsalva and courses between the ascending aorta and pulmonary artery with proximal ectasia demonstrated by multi detector computerizes tomography (MDCT) heart angiography. artery [2]. And anomalous origin of the right coronary from the left aortic sinus was first described in 1948 by White and Edwards [3].

There are three subtypes based on the anatomic course of the artery. The aberrant vessel may cause posterior to the aorta (retroaortic), between the ascending aorta and pulmonary trunk (interarterial), or anterior to the pulmonary trunk. In this case we illustrated interarterial subtype. The interarterial subtype has been reported to be associated with sudden death, angina pectoris or myocardial infarction in the absence of atherosclerosis [3]. In the previous study this anomaly named malignant right coronary artery anomaly. The pathophysiologic basis for this association, however, is unclear. Mechanical compression of the right coronary artery by the great vessels is the usual explanation, because the right coronary artery generally courses between the aorta and the pulmonary artery to its normal position. Others have suggested that the proximal portion of the right coronary artery, situated between the aorta and the pulmonary artery, might be more prone to spasm then it would be otherwise [4]. Taylors et al. suggested that the oblique angle at the juncture of the anomalous right coronary artery and the left coronary sinus produces a slit-like orifice in the aortic wall that can collapse during exercise [5]. Identification of anomalous coronary arteries is frequently difficult with conventional coronary angiography because of the lack of 3-dimensional (D) information related to the course of the coronary arteries to the great vessels [6]. Magnetic resonance imaging (MRI) is an alternative, noninvasive imaging modality that feasibly can be used for the detection of anomalous coronary arteries [7], but 3-D information had not been available until recently [8].

In addition, detection of atherosclerotic coronary artery plaques that may overlap the anomalous coronary artery system is not possible by MRI because of its limited spatial resolution. Multislice computed tomography (MSCT) provides excellent spatial resolution, which allows assessment of not only the atherosclerotic coronary artery disease [9], but also of congenital coronary artery anomalies such as coronary arteriovenous fistula [10]. TEE has been utilized to detect coronary anomalies; the operator may miss the diagnosis.

In this case we used TTE, TEE and MDCT Heart Angiography. TTE showed suspicious images for aneurysm of left sinus valsalva and this suspicious finding supported by TEE. Then the right coronary artery which arises from the left sinus valsalva and courses between the ascending aorta and pulmonary artery with proximal ectasia demonstrated by MDCT Heart Angiography. 


\section{REFERENCES}

[1] O. Yamanaka and R. E. Hobbs, "Coronary Artery Anomalies in 126, 595 Patients Undergoing Coronary Angiography," Catheterization and Cardiovascular Diagnosis, Vol. 21, No. 1, 1990, pp. 28-40.

[2] D. Kimbiris, A. S. Iskandrian, B. L. Segal and C. E. Bemis, "Anomalous Aortic Origin of Coronary Arteries," Circulation, Vol. 58, No. 4, 1978, pp. 606-615.

[3] N. K. White and J. E. Edwards, "Anomalies of the Coronary Arteries; Report of Four Cases," Archives of Pathology, Vol. 45, No. 6, 1948, pp. 766-771.

[4] A. J. Taylor, K. M. Rogan and R. Virmani, "Sudden Cardiac Death Associated with Isolated Congenital Coronary Artery Anomalies," Journal of the American College of Cardiology, Vol. 20, No. 3, 1992, pp. 640-647. doi:10.1016/0735-1097(92)90019-J

[5] B. Kaku, H. Kanaya, M. Ikeda, Y. Uno, S. Fujita and F. Kato, et al., "Acute Inferior Myocardial Infarction and Coronary Spasm in a Patient with an Anomalous Origin of the Right Coronary Artery from the Left Sinus of Valsalva," Japanese Circulation Society, Vol. 64, No. 8, 2000, pp. 641-643. doi:10.1253/jcj.64.641

[6] H. Serota, C. Barth, C. A. Seuc, M. Vandormael, F. Aguirre and M. J. Kern, "Rapid Identification of the Course of Anomalous Coronary Arteries in Adults: The
'Dot and Eye' Method," The American Journal of Cardiology, Vol. 65, No. 13, 1990, pp. 891-898. doi:10.1016/0002-9149(90)91432-6

[7] L. B. Haramati, J. S. Glickstein, H. Issenberg, N. Haramati and G. A. Crooke, "MR Imaging and CT of Vascular Anomalies and Connections in Patients with Congenital Heart Disease: Significance in Surgical Planning," Radio Graphics, Vol. 22, No. 2, 2002, pp. 337 349.

[8] N. H. Bunce, C. H. Lorenz, J. Keegan, J. Lesser, E. M. Reyes, D. N. Firmin, et al., "Coronary Artery Anomalies: Assessment with Free-Breathing Three-Dimensional Coronary MR Angiography," Radiology, Vol. 227, No. 1, 2003, pp. 201-208.

[9] S. Achenbach, T. Giesler, D. Ropers, S. Ulzheimer, H. Derlien, C. Schulte, et al., "Detection of Coronary Artery Stenoses by Contrast-Enhanced, Retrospectively Electrocardiographically-Gated, Multislice Spiral Computed Tomography," Circulation, Vol. 103, No. 21, 2001, pp. 2535-2538.

[10] Y. Sato, M. Mitsui, H. Takahashi, T. Miyazawa, H. Okabe, F. Inoue, et al., "A Giant Left Circumflex Coronary Artery-Right Atrium Arteriovenous Fistula Detected by Multislice Spiral Computed Tomography," Heart Vessels, Vol. 19, No. 1, 2004, pp. 55-56. doi:10.1007/s00380-003-0707-y 